\title{
Consolidação fiscal nos Estados brasileiros: uma análise de duração
}

Bruno de Paula Rocha Doutor em Economia, IPE-USP

Fabiana Rocha

Departamento de Economia da Universidade de São Paulo

\section{Palauras-chave}

ajuste fiscal, análise de duração.

Classificação JEL H70; C41.

Key words

fiscal consolidation,

duration analysis.

JEL Classification H70; C41.

\section{Resumo}

O objetivo deste artigo é examinar a persistência das consolidações fiscais dos Estados brasileiros no período 1986-2001, usando a metodologia dos modelos de duração. Dessa forma, procura-se estabelecer quais características dos Estados explicam a probabilidade de que esse se mantenha numa situação de ajuste fiscal uma vez que já se encontrava na mesma anteriormente. Os resultados nãoparamétricos sugerem que a probabilidade de que uma consolidação fiscal seja mantida cai rapidamente depois do primeiro ano e decresce dramaticamente depois do segundo ano. A análise paramétrica foi feita buscando-se controlar para mais variáveis, além do tempo, que pudessem influenciar a probabilidade de uma consolidação fiscal terminar. Várias especificações foram testadas, e as variáveis que apareceram como importantes foram: o Número de Falhas, a razão Despesa com Pessoal/Receita Corrente Líquida, a dummy para a Constituição de 1988, a dummy para a Lei de Refinanciamento n. 9.496/97 e a polarização nas preferências dos partidos que compõem a Assembléia Legislativa.

\section{Abstract}

The objective of this paper is to analyze the duration of fiscal consolidation of Brazilian states in the period 1986-2001. For this propose, we applied the duration models methodology. We sought to establish the main characteristics that explain the probability that a state would remain in fiscal balance, once it has achieved that position. The non-parametric results suggest that the probability that fiscal consolidation will be maintained falls dramatically after the first year and even more after the second year. Parametric analysis shows that there is a core of relevant variables, such as the Number of Failures, the Personnel Costs/Net Current Revenue ratio, the dummy variable for the years before the Brazilian Constitution of 1988, the dummy variable for the years after the refinance law 9496/97 and the polarization in the preferences of the parties that compose the Legislative Assembly. 


\section{1_Introdução}

A preocupação crescente com o equilíbrio fiscal tem levado ao aparecimento de alguns estudos avaliando diferentes aspectos dos ajustamentos fiscais. No que diz respeito às finanças públicas estaduais, a principal preocupação é com os determinantes do comportamento fiscal dos Estados. Cossío (2001) procura avaliar quais os principais fatores econômicos e políticos que explicam as despesas estaduais, ao passo que Botelho (2002) busca determinar quais características dos Estados aumentam a probabilidade de que esses realizem um ajustamento fiscal.

O que chama a atenção nesses trabalhos é a pouca persistência dos ajustes fiscais. Como nota Cossío, durante o período 1985-1997,

a maioria dos Estados adotou uma politica de stop-and-go, isto é, as contrações foram seguidas de expansões fiscais e viceversa, impedindo que se extraia tendências regulares de deterioração ou de melhoras progressivas na situação fiscal dos Estados (Cossío, 2001, p. 485)

Desse modo, o objetivo deste trabalho é avaliar os determinantes da duração dos ajustes fiscais dos Estados brasileiros. Mais precisamente, procura-se estabelecer quais características dos Estados explicam a probabilidade de que este se mantenha numa situação de ajuste fiscal visto que já se encontrava nessa anteriormente.

$\mathrm{O}$ artigo está organizado da seguinte maneira. A segunda seção apresenta os critérios comumente usados na literatura para identificar episódios de consolidação fiscal e define o critério escolhido para caracterizar os ajustamentos fiscais dos Estados brasileiros. Na terceira seção, apresentamse os conceitos básicos dos modelos de duração. A quarta seção resume e discute os resultados das estimações. Na quinta seção, faz-se uma análise de sensibilidade dos resultados a uma nova definição de postura fiscal. Por último, a sexta seção apresenta as conclusões finais e indicações para pesquisas futuras.

\section{2_ Definição de ajuste fiscal e duração das consolidações fiscais nos Estados}

A definição de ajustamento fiscal e o estabelecimento de regras para identificação de episódios de consolidação e expansão são inevitavelmente marcados por algum grau de arbitrariedade.

De acordo com Alesina e Perotti (1997), um período de política fiscal apertada (consolidação fiscal) corresponde a um ano em que o déficit primário ciclicamente ajustado em porcentagem do PIB cai mais 
do que $1,5 \%$ ou um período de dois anos consecutivos nos quais o déficit primário ciclicamente ajustado em porcentagem do PIB cai pelo menos $1,25 \%$ ao ano em ambos os anos.

McDermott e Wescott (1996), por outro lado, apresentam três definições diferentes de uma política fiscal apertada:

1. Quando o saldo primário ciclicamente ajustado em relação ao PIB melhora pelo menos $1,5 \%$ ao longo de dois anos e não cai em nenhum dos dois anos.

2. Quando o saldo primário ciclicamente ajustado em relação ao PIB melhora pelo menos 1,5\% em um ano. Esta regra tem dois problemas. Primeiro, ela inclui episódios que podem ser revertidos logo no ano seguinte. Segundo, ela não insere episódios de melhoras pequenas, mas persistentes (que ocorrem ao longo de mais de um ano).

3. Quando o saldo primário ciclicamente ajustado em relação ao PIB melhora pelo menos $2 \%$ ao longo de três anos e não cai em nenhum dos três anos. Essa regra, contudo, pode apontar para consolidações quando elas efetivamente já acabaram. Tal possibilidade ocorreria quando, por exemplo, gran- de parte do ganho pode ter ocorrido no primeiro ano, mas já no terceiro parece haver uma indicação de que o sinal será invertido. Uma vez que a idéia é definir episódios em que houve uma mudança clara na esfera fiscal, um critério mais rigoroso é preferível visto que ele elimina ajustamentos prolongados, mas pequenos.

Shi (2002) segue Alesina e Perotti (1997) para avaliar os ajustamentos fiscais na América Latina. Define um episódio de ajustamento fiscal ou política de contração fiscal como um ano em que o saldo primário ciclicamente ajustado melhora pelo menos $3 \%$ do produto, ou o primeiro de alguns anos consecutivos em que o saldo primário ciclicamente ajustado melhora pelo menos 2\% ao ano. Ele procura, assim, usar um critério mais rigoroso tentando eliminar ajustamentos pequenos, mas prolongados, e centrando nos casos em que houve de fato uma mudança clara de comportamento fiscal.

Assim, uma primeira tentativa para definir a variável dependente seria usar um dos critérios acima para definir os episódios de consolidação fiscal e, então, determinar o intervalo de tempo que cada consolidação dura. Alguns problemas surgem imediatamente: 
1. Que valor de corte usar. Caso se decida usar os 3\% sugeridos por Shi (2002), ainda que seja possível definir 45 episódios de consolidação fiscal, somente cinco duraram mais de um ano.

2. Os episódios fiscais são definidos com base no saldo primário ciclicamente ajustado. Existem diversas maneiras de se calcular o saldo estrutural ou ciclicamente ajustado, ${ }^{1}$ e a falta de consenso com relação à melhor maneira de fazer isso seria um problema adicional.

Em suma, a arbitrariedade com relação à escolha do valor de corte seria somada à arbitrariedade com relação ao procedimento para calcular o saldo primário estrutural. Cossío (2001) usa uma variante da metodologia de Blanchard (1990) para identificar a postura fiscal dos Estados. Em vez de calcular o saldo do governo que teria ocorrido caso o desemprego tivesse sido o mesmo do ano anterior, ele ajusta o saldo primário para variações tanto no nível de atividade quanto na taxa de inflação. ${ }^{2}$ A taxa de inflação é também considerada por causa da indexação assimétrica das receitas e despesas do governo. A indexação menor das despesas, em contraposição à indexação da maior parte das receitas, pode explicar em grande medida as variações do resultado primário nos períodos de aceleração/desaceleração da inflação.

Para simplificar, será usado como medida de comportamento fiscal a variação no resultado primário efetivamente observado como porcentagem do produto de um ano em relação ao ano anterior. Seguindo Cossío (2001), uma elevação no resultado primário como porcentagem do PIB (ou impulso fiscal) igual ou superior a 0,5 ponto porcentual representa uma contração fiscal. Se uma mudança dessa magnitude ocorre por apenas um período seguido, o episódio fiscal durou um ano e, assim, sucessivamente. ${ }^{3,4} \mathrm{Na}$ Tabela 1 são apresenta os ajustamentos fiscais identificados para cada um dos Estados durante o período 1986-2001.

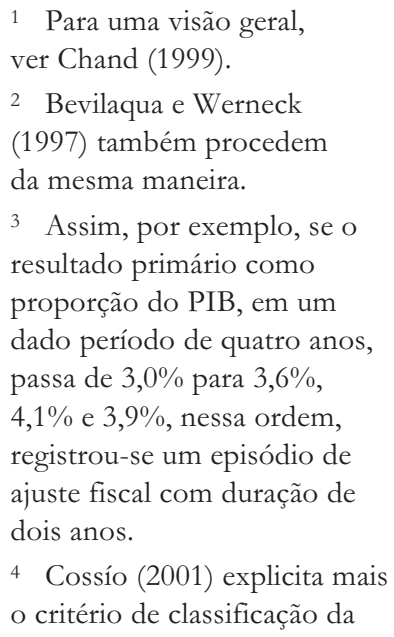
postura fiscal. Dessa forma, uma contração fiscal corresponde a uma mudança no resultado primário como porcentagem do PIB maior do que $1,5 \%$, uma contração média entre $0,5 \%$ e $1,5 \%$, uma expansão média entre $-0,5 \%$ e $-1,5 \%$ e uma expansão forte mais do que $-1,5 \%$. Uma postura fiscal neutra corresponde a uma mudança no resultado primário entre $0,5 \%$ e $-0,5 \%$ do PIB. 
Tabela 1_Ajustamentos fiscais acima de $\mathbf{0 , 5} \%$ do PIB

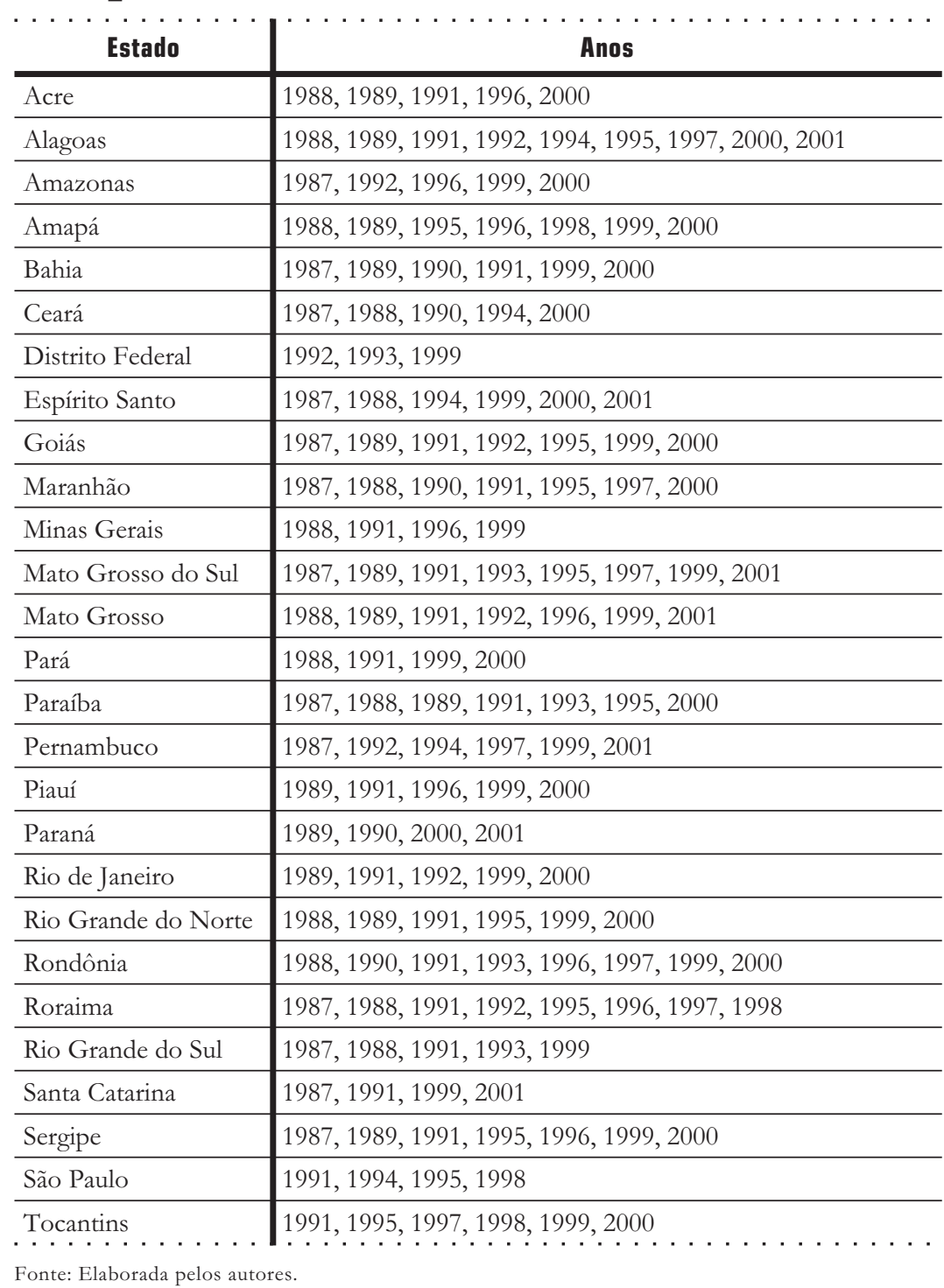


$\mathrm{Na}$ Tabela 2, apresenta-se a estrutura dos dados de duração. Tem-se um total de 109 observações. A maior parte dos ajustamentos $(61,47 \%)$ dura somente um ano, ou seja, observa-se a melhora na postura fiscal num ano e logo em seguida uma reversão desses resultados. Observam-se, ainda, 36 episódios de ajustamento de 2 anos, 4 episódios de ajustamento de 3 anos e 2 episódios de ajustamento de 4 anos. Assim, os ajustamentos fiscais dos Estados são pouco sustentáveis, no sentido de que são rapidamente revertidos. Os ajustamentos fiscais duram em média 1,45 anos com desvio-padrão de $0,66 .^{5}$

Embora a preocupação de Shi (2002) não seja com a duração dos ajustamentos fiscais na América Latina, mas com os determinantes das consolidações fiscais bemsucedidas e com as conseqüências macroecônomicas dessas, ele observa também um padrão de curta duração dos ajustes fiscais. O autor identifica 29 episódios de consoli-

Tabela 2_Ajustamentos fiscais

\begin{tabular}{|c|c|c|c|}
\hline Duração dos ajustes fiscais & Freqüência & Percentual & Acumulado \\
\hline 1 & 67 & 61.47 & 61.47 \\
\hline 2 & 36 & 33.03 & 94.5 \\
\hline 3 & 4 & 3.67 & 98.17 \\
\hline 4 & 2 & 1.83 & 100 \\
\hline Total & 109 & 100 & \\
\hline
\end{tabular}

Fonte: Elaborada pelos autores. dação fiscal, com duração máxima de 4 anos, sendo que somente metade dura mais de 2 anos.

Illera e Mulas-Granados (2002), em um trabalho semelhante ao aqui proposto, procuram examinar a duração das consolidações fiscais de 15 países membros da União Européia durante o período 1960-2000. Os autores definem um ano de consolidação fiscal como aquele em que a variação do saldo fiscal ciclicamente ajustado é maior do que zero. A duração média das consolidações fiscais é de cerca de 2 anos, valor não muito diferente do encontrado aqui, embora o número máximo de anos que uma consolidação dura seja de 10 anos, bastante superior ao padrão encontrado para os Estados brasileiros. Quando, a fim de fazer uma análise de sensibilidade, Illera e Mulas-Granados (2002) mudam o limiar de 0 para 1\%, a duração média é muito menor (1,29 anos), e a duração máxima passa a ser de 4 anos.
Uma discussão adicion

adicional na literatura de ajustamentos fiscais, mas que não será tratada aqui, diz respeito à definição de sucesso. Shi (2002) define como ajustamentos fiscais bemsucedidos ou duradouros aqueles que duram pelo menos dois anos depois que começaram, ou seja, aqueles que começam no ano $t \mathrm{e}$ duram até o ano $t+k \mathrm{com}$

$k \geq 2$. No entanto, para outros autores, o sucesso não está relacionado à duração. Alesina e Perotti (1997), por exemplo, definem medidas de sucesso com base tanto no comportamento do estoque da dívida quanto do fluxo de déficits primários nos anos que seguem o período de consolidação fiscal. McDermott e Wescott (1996) olham para mudanças na relação dívida/PIB. 
6 Poderia ser argumentado que a evidência encontrada para os Estados brasileiros decorra, em parte, do rigor empregado no critério de seleção de ajustes, já que a manutenção de um dado nível de resultado primário como proporção do PIB é interpretada como o fim de um episódio de consolidação fiscal. Na seção 5 , um critério alternativo (e, aparentemente, mais flexível) para definição de ajuste fiscal é utilizado, mas a extensão média dos ajustes brasileiros mantém-se praticamente inalterada.
Desta forma, fica claro que a pequena duração dos ajustamentos fiscais não é uma característica específica dos Estados brasileiros, representando uma dificuldade geral, verificada em diferentes economias. ${ }^{6}$

Tal como em Illera e Mulas-Granados (2002), o instrumental econométrico utilizado neste trabalho será a análise de duração, cujas principais características descrevemos a seguir.

\section{Análise de duração}

No presente artigo, em que o objetivo é avaliar a probabilidade de manutenção de um ajustamento fiscal, define-se $T$ como uma variável aleatória que mede o intervalo de tempo entre o começo e o fim de um ajustamento fiscal. Mais precisamente, as observações consistem em durações observadas de cada episódio de consolidação fiscal na amostra. A probabilidade de um ajustamento fiscal durar mais do que $t$ períodos é chamada função sobrevivência (survivor function) e tem a seguinte forma geral:

$S(t)=\operatorname{Pr}[T>t]=1-F(t)$

onde $F(t)$ é a função de distribuição cumulativa da variável de duração e a função densidade de probabilidade é igual a $f(t)=-S^{\prime}(t)$. Embora a distribuição da variável de duração possa ser descrita por $F(t)$ ou $f(t)$, ela é, geralmente, caracterizada pela função risco (hazard function):

$$
\begin{aligned}
h(t) & =\lim _{d t \rightarrow 0} \frac{P[t<T<t+d t \mid T>t]}{d t}= \\
& =\frac{-S^{\prime}(t)}{S(t)}
\end{aligned}
$$

A função risco, $h(t)$, relaciona a cada duração $t$ a probabilidade de a falha ocorrer um instante de tempo infinitesimalmente após $t$, condicionado ao fato de a duração ter permanecido até aquele instante. Mais precisamente ela fornece, para cada duração, a probabilidade de que o episódio de consolidação termine (e um episódio de expansão comece), condicional à duração da consolidação até aquele momento.

Existe uma série de vantagens estatísticas em estimar $h(t)$ em vez de $F(t)$ ou $f(t)$ (ver Cox e Oakes, 1984). Obviamente, uma vez obtidas estimativas de $h(t)$, estimativas de $F(t)$ e $f(t)$ são prontamente obtidas usando:

$$
\begin{aligned}
& F(t)=1-\exp \left[-\int_{0}^{t} h(u) d u\right] \\
& \text { e } f(t)=F^{\prime}(t),
\end{aligned}
$$

onde a integral entre colchetes é denominada função risco integrada (integrated hazard). Ela não tem uma interpretação ade- 
quada, mas, como se verá mais adiante, constitui um ingrediente básico do teste de especificação do modelo.

A função risco e a função sobrevivência podem ser estimadas usando-se métodos não-paramétricos, semiparamétricos e paramétricos. Aqui serão utilizadas todas as metodologias.

\section{4_Resultado das estimações}

\section{1_Métodos não-paramétricos}

Os métodos não-paramétricos para estimação da função risco e da função sobrevivência são bastante úteis pela sua simplicidade. Como representam uma abordagem estritamente empírica, sem hipótese acerca das distribuições envolvidas, consistem numa boa alternativa para uma análise preliminar dos dados.

A análise não-paramétrica é usada para estimar a função risco não condicional que registra todas as observações para as quais há uma mudança. A estimativa de KaplanMeier (1958) é normalmente usada, em que a função risco é calculada como:

$\hat{b(t)}=\frac{d_{t}}{n_{t}}$,

onde $d_{t}$ representa o número de falhas registradas, ou seja, a quantidade de Esta- dos brasileiros que mudaram de estado da natureza, passando da situação de ajuste para a de expansão fiscal, no instante $t$, líquido das censuras observadas, e $n_{t}$ é a população sobrevivente no momento $t$, antes que a mudança ocorra. Deve-se notar, portanto, que o estimador de Kaplan-Meier é robusto mesmo na presença de observações censuradas, ou seja, ajustes fiscais cuja duração não tenha chegado ao fim em 2001.

Na Tabela 3, apresenta-se o número de falhas e a população sobrevivente em cada momento $t$, assim como a função de sobrevivência Kaplan-Meier. A probabilidade de um ajuste fiscal durar mais do que dois anos é de 0,08 . Na verdade, a probabilidade de continuação cai muito rapidamente quando a duração é maior do que um período.

\section{Tabela 3_Estimação não-paramétrica para a função sobrevivência Método de Kaplan-Meier}

\begin{tabular}{c}
$\begin{array}{c}\text { Duração dos } \\
\text { Ajustes Fiscais }\end{array}$ \\
\hline 1
\end{tabular}

Fonte: Elaborada pelos autores. 


\section{2_ Métodos semiparamétricos e paramétricos}

Os métodos de estimação semiparamétricos e paramétricos permitem a inclusão de variáveis explicativas, filtrando o efeito marginal de cada uma delas sobre a função risco e a duração esperada para os ajustes fiscais.

Dependendo das hipóteses feitas sobre a natureza da distribuição do tempo até a falha, diferentes tipos de modelo de risco podem ser especificados. Suponhamos que $h(t \mid X, \beta)$ seja a função risco no tempo $t$ para um Estado qualquer, onde $X$ representa um conjunto de variáveis que afetam a probabilidade de saída de um ajuste fiscal, e $\beta$ os coeficientes a serem estimados e que descrevem como cada variável característica afeta a probabilidade de saída do ajuste. Num modelo de risco proporcional, temos:

$h(t \mid X, \beta)=h_{0}(t) \Psi(X, \beta)$,

onde $\Psi(X, \beta)$ é alguma função de $X$, tal que $\Psi(X=0, \beta)=1$ e $h_{0}(t)$ é uma função risco para uma consolidação fiscal com $X=0$, denominada baseline hazard function. Se as variáveis explicativas forem centralizadas, de forma que um ajuste fiscal com $X=0$ tem valores iguais às médias populacionais, então $h_{0}(t)$ pode ser pensado como a função risco de um ajuste fiscal "médio" na população. Dessa forma, num modelo de risco proporcional, o efeito das va- riáveis explicativas é multiplicar a função risco de um ajuste fiscal médio, $h_{0}(t)$, por alguma função $\Psi(X, \beta)$ dos desvios das variáveis explicativas de seus valores médios.

Um caso especial de modelo de risco proporcional, é o modelo de Cox (1972), no qual $\Psi(X, \beta)=\exp \left(X^{\prime} \beta\right)$, que será utilizado aqui. A função risco é então dada por:

$h(t \mid X, \beta)=b_{0}(t) \exp \left(X^{\prime} \beta\right)$

O modelo de Cox, em geral, é denominado semiparamétrico, sendo $h_{0}(t)$ sua parte não-paramétrica e $\exp \left(X^{\prime} \beta\right)$ sua parte paramétrica. $\mathrm{O}$ modelo toma por hipótese que a função risco baseline $h_{0}(t)$ é arbitrária e depende somente do tempo. Além disso, não são requeridas hipóteses distributivas para estimar $\beta$ ou $h_{0}(t)$. A segunda parte de (3), por outro lado, depende do vetor dos parâmetros de regressão $\beta$.

A função de sobrevivência correspondente para o modelo de risco proporcional de Cox, que é usada para calcular a probabilidade de um ajuste fiscal durar mais do que um determinado período de tempo, é dada por:

$S(t \mid X, \beta)=S_{0}(t)^{\exp \left(X^{\prime} \beta\right)}$

onde $S_{0}(t)=\exp \left[-\int_{0}^{t} h_{0}(u) d u\right]$ é a função sobrevivência correspondente à função risco baseline $h_{0}(t)$. Como na função 
risco, $S_{0}(t)$ é denominada função sobrevivência baseline (baseline survivor function) e depende somente do tempo. Ela é a mesma para todos os ajustes fiscais. A integral entre parênteses, por correspondência, é denominada função risco integrada baseline (baseline integrated hazard).

Embora o procedimento semiparamétrico dispense hipóteses acerca da forma funcional da função risco básico, ao adotar a hipótese de proporcionalidade, ela restringe a maneira pela qual as variáveis explicativas afetam a função de risco. O método paramétrico, por sua vez, toma maior rigidez com relação à adoção de distribuições específicas para a variável aleatória de duração, mas permite estimar a influência de cada uma das variáveis explicativas sobre a duração esperada dos ajustes fiscais. Essa abordagem em que, em vez da função risco, a duração esperada é utilizada como variável dependente refere-se ao modelo de aceleração de saída. Mais especificamente, o logaritmo natural da variável de duração é escrito como função linear das variáveis explicativas. O modelo de aceleração de saída é uma transformação do modelo de riscos proporcionais apresentado acima, que permite uma diferente interpretação dos dados. No entanto, esse modelo conserva as mesmas características estatísticas do modelo de riscos proporcionais. Uma descri- ção detalhada a respeito pode ser vista em Kiefer (1988).

As formas paramétricas específicas para a função $h_{0}(t)$ mais usadas são a exponencial, Weibull e log-logística. A escolha da distribuição adequada deve ser feita com base nas características de cada uma delas e sua relativa adequação ao fenômeno analisado. A distribuição exponencial apresenta como principal característica uma função risco constante no tempo. A distribuição de Weibull, por sua vez, flexibiliza a parametrização exponencial, permitindo um formato monotonicamente crescente ou decrescente para a função risco. Por último, a distribuição log-logística permite um comportamento não monotônico da função risco.

\subsection{1_Variáveis explicativas}

A fim de analisar os fatores que explicam a probabilidade de uma consolidação fiscal terminar, usam-se dois conjuntos de variáveis. Primeiro, um conjunto de variáveis econômicas e institucionais que se acredita estarem relacionadas a diferentes durações de consolidações fiscais. Depois, um conjunto de variáveis políticas que na literatura aparecem como importantes determinantes não-econômicas dessas consolidações.

Com base na execução orçamentária dos Estados, foi criada a primeira variá- 
' " " " " " " " ervado por Botelho, "para esses Estados o acesso ao financiamento é mais restrito e a capacidade técnica do corpo funcional é limitada em relação à proposição de engenharias financeiras para obtenção de financiamentos. Nos Estados com maior base econômica e, portanto, maior força politica, os bancos estaduais receberam tratamento diferenciado ante os passivos descobertos. Os passivos descobertos nada mais eram do que financiamentos excessivos aos seus respectivos controladores" (Botelho, 2002, p. 46). vel explicativa Despesa de Pessoal/Receita Corrente Líquida. Essa é calculada como a razão entre as Despesas de Pessoal e Encargos e a Receita Corrente Líquida (RCL), em que a Receita Corrente Líquida é igual à Receita Corrente deduzida das Transferências Correntes aos municípios. $\mathrm{O}$ gasto com pessoal corresponde ao principal item de despesa corrente dos Estados, incluindo gastos como aposentadorias e pensões. Como essas contas não são passíveis de corte, a relação Despesa de Pessoal/Receita Corrente Líquida mede o nível de rigidez orçamentária e, dessa forma, mostra o grau de dificuldade em se realizar um ajuste fiscal.

A execução orçamentária dos Estados fornece também o grau de dependência dos Estados de transferências de receitas da União (Receita Tributária/Receita Corrente), calculado como a participação da Receita Tributária no total da Receita Corrente. Seria de se esperar que, quanto maior a dependência de transferências de recursos, maiores os gastos associados. Isso porque a autoridade local não internaliza completamente os efeitos de suas decisões de gasto sobre todo o orçamento, resultando no fenômeno conhecido como flypaper effect. Esse implica mais especificamente que as despesas públicas reagem de forma muito mais forte às transferências do que ao aumento da renda privada.
Entretanto, o sistema federativo brasileiro é claramente redistributivo. Com isso, maiores transferências são destinadas aos Estados mais pobres. Assim, esse indicador também está captando as características intrínsecas associadas à fragilidade da base econômica. ${ }^{?}$

A idéia é verificar se a característica frágil base econômica predomina sobre o "flypaper effect". Se esse é o caso, os governadores de Estados fortemente dependentes de transferências da União, mesmo sendo mais propensos a gastar, encontram dificuldades de obter financiamento para tais gastos e, portanto, gastam menos. Com isso, aumenta a probabilidade de manutenção do ajustamento fiscal.

Foi considerada também uma variável que mede a força da consolidação (Impulso Fiscal). Essa variável corresponde ao tamanho do impulso fiscal, ou seja, da mudança no saldo fiscal. Acredita-se que, quanto maior o impulso fiscal, ou seja, maior a magnitude do ajustamento, maior a probabilidade de que ele seja mais duradouro. Isso porque tal situação sinalizaria maior comprometimento com a boa prática fiscal. Por outro lado, quanto maior o ajustamento feito, mais difícil é conseguir mantê-lo, uma vez que cortes adicionais envolvem disputas políticas mais acirradas. 
Foi incluída uma variável medindo o número de falhas (Número de falhas). Essa variável mede o número acumulado de falhas (términos de consolidação fiscal) que foi observado em cada Estado antes da consolidação corrente. O número de falhas seria uma medida de reputação em termos de consolidações fiscais mais duradouras. Espera-se que, quanto maior o número acumulado de falhas, menos estável o Estado é em manter uma política fiscal apertada e, portanto, maior a probabilidade de que a consolidação fiscal termine mais rapidamente.

A qualidade do ajustamento (Composição) mede a importância relativa da redução dos gastos e do aumento dos impostos para a consolidação fiscal. Assim, uma dummy igual a 1 representa uma situação em que a melhora do orçamento resultou majoritariamente de uma redução nas despesas. Acredita-se que, se esse é o caso, menor a probabilidade de que a consolidação vá terminar. Cortes nos gastos indicam compromisso maior com o equilíbrio orçamentário do que aumentos de impostos, implicando maior probabilidade de duração (Alesina e Perotti, 1997; McDermott e Wescott, 1996).

Outras duas variáveis dummy foram consideradas objetivando captar possíveis efeitos das mudanças institucionais ocorridas durante o período analisado. A primei- ra corresponde à promulgação da nova Constituição em 1988, e a segunda à adoção dos Programas de Ajuste Fiscal dos Estados, segundo o refinanciamento regulamentado pela Lei n. 9.496/97. Foi criada ainda uma dummy relativa a Ano Eleitoral. Em anos eleitorais, espera-se que haja certo grau de desajuste fiscal.

As variáveis políticas foram obtidas valendo-se da base de dados eleitorais do Laboratório de Estudos Experimentais Leex/IUPERJ.

O índice de Fracionalização das Preferências, construído para captar a dispersão/ concentração das preferências do eleitorado em relação aos candidatos ao governo estadual, é dado por:

$F=1-\sum v_{i}^{2}$

onde $v_{i}$ é a proporção de votos obtida por cada candidato.

$O$ índice $F$ baseia-se na probabilidade de que dois eleitores escolhidos aleatoriamente tenham votado em candidatos diferentes em uma dada eleição. ${ }^{9}$ A contribuição dos candidatos mais bem votados para o resultado final do índice é elevada uma vez que a proporção de votos de cada candidato é elevada ao quadrado. Tal variável tem como objetivo tentar captar o argumento desenvolvido por Alesina e Tabellini (1987), segundo o qual, quanto maior a

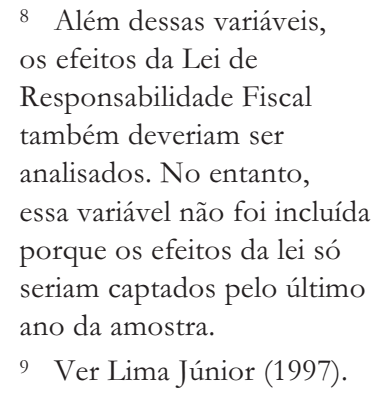


10 Foram considerados

os seguintes partidos de esquerda: PT, PCB, PCdoB, PPS, PSB, PV, PDT e PSTU. divergência entre as preferências dos eleitores, maior probabilidade de aumentar o endividamento. Eles mostram que, num modelo em que as decisões são tomadas pela regra majoritária, o "teorema do eleitor mediano" implica que a política a ser adotada é a preferida pelo eleitor mediano. Dado que existe incerteza com relação às preferências majoritárias futuras sobre a composição do gasto, o eleitor mediano atual usa a emissão de dívida para direcionar a composição futura do gasto a seu favor. Assim, quanto maior a divergência entre as preferências dos eleitores, maior a dívida e, portanto, menor a probabilidade de manutenção do ajustamento fiscal.

Para mensurar o número de partidos com relevância na composição da Assembléia Legislativa, é utilizada a variável Partidos Efetivos, dada pela seguinte expressão:

$N=\frac{1}{\sum c_{i}^{2}}$

onde $c_{i}$ é a proporção de candidatos eleitos na Assembléia pelo partido $i$.

Esse índice aproxima-se de uma avaliação intuitiva do número de partidos relevantes na Assembléia de cada Estado. A fragmentação partidária implica a inexistência de maiorias absolutas e, portanto, a necessidade de negociação para a formação da base de apoio parlamentar. Como essa nego- ciação envolve a concessão de benefícios e procura atender distintos grupos de interesse que barganham favores em troca de apoio político, o resultado é o comportamento clientelista conhecido na literatura como logrolling ou pork barril.

A evidência empírica internacional indica que governos compostos por vários partidos ou governos divididos (Executivo e Legislativo comandados por partidos diferentes) têm maiores dificuldades para fazer um ajustamento fiscal. Alt e Lowry (1994) e Alesina e Rosenthal (1995) mostram ainda que governos divididos têm chance menor de promover ajustamentos fiscais bem-sucedidos. No caso brasileiro, Schneider (2000) argumenta que Estados com maior fragmentação (Pernambuco e Rio Grande do Sul) apresentam maiores dificuldades orçamentárias do que Estados com menor fragmentação (Bahia e Paraná).

O indicador de polarização das preferências dos partidos (Polarização da Coligaşão) foi construído representando a participação dos partidos de esquerda no total de assentos da Assembléia Legislativa. ${ }^{10}$ De acordo com Alesina e Tabellini (1987), a trajetória da dívida pública resulta da interação estratégia de governantes diferentes que estão no poder em períodos diferentes. A quantidade de empréstimos utilizada para financiar o déficit público hoje é tanto maior quanto: 
1. Maior a divergência entre partidos, isto é, maior a polarização de suas preferências na composição dos gastos do governo.

2. Maior a probabilidade que o governo atual não seja reeleito amanhã.

3. Maior é a restrição submetida ao governo de prover obrigatoriamente determinado tipo de gasto público em níveis mínimos. ${ }^{11}$

Em suma, uma maior polarização dos partidos implica maior acumulação de dívida. Essa variável capta, assim, o reflexo da polarização dos partidos em termos de ideologia sobre o desempenho fiscal.

Outra variável explicativa indicada pela teoria seria a probabilidade de não-reeleição. De acordo com Alesina e Tabellini (1987), quanto maior a probabilidade de um governo não ser reeleito, maior o déficit e a dívida pública. Grilli, Masciandaro e Tabellini (1991) também mostraram que déficits orçamentários são negativamente correlacionados com a durabilidade do governo, ou seja, quanto maior a permanência de um determinado partido no poder, menor o déficit. ${ }^{12}$ Contrariamente a esses modelos de controle político, os modelos orçamentários oportunistas indicam que a reeleição levaria a um aumento nos déficits. Isso ocorreria porque o governo incumbente usaria a política fiscal para influenciar a decisão dos eleitores. Em Rogoff e Silbert (1988), por exemplo, antes das eleições os impostos seriam reduzidos na tentativa de garantir a reeleição. Visando captar os incentivos gerados pela reeleição, utilizamos um indicador de Permanência no Poder como uma proxy para a probabilidade de reeleição. Trata-se de uma variável dummy, indicando as situações em que o atual partido governante for o mesmo da legislatura anterior.

A ideologia do partido do governador foi considerada por meio de uma variável dummy assumindo o valor 1 para os Partidos de Esquerda ${ }^{13}$ e 0 para os demais partidos. Alguns fatos estilizados sobre ideologia aparecem na literatura:

1. Os partidos de esquerda são relativamente mais favoráveis à intervenção do governo na área econômica do que os partidos de direita.

2. Os partidos de esquerda têm maior preocupação com os problemas sociais e acreditam que esses podem ser resolvidos com maior participação do Estado.

3. Em contrapartida a (2), os partidos de direita acreditam mais nos mecanismos de mercado.

Alt e Lowry (1994), em um estudo do comportamento fiscal dos Estados americanos entre 1968-1987, mostram que impostos

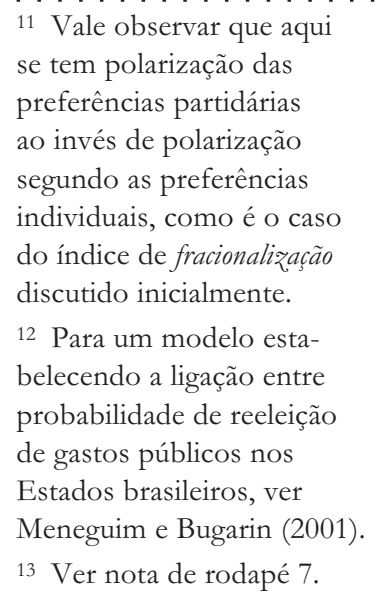


e despesas são significativamente maiores quando o governador pertence ao partido democrata. Kontopoulus e Perotti (1999), por sua vez, num estudo para países da OCDE, encontram evidência de que países com governos de esquerda gastam mais do que os de direita. Assim, espera-se que a duração seja menor quando o governo é de esquerda.

A Tabela 4 resume as variáveis explicativas usadas nos modelos semiparamétri- cos e paramétricos. Os modelos serão estimados inicialmente com todas as variáveis explicativas, sendo retiradas as que não forem estatisticamente significantes. Em seguida, é feito um teste a fim de se avaliar a significância conjunta das variáveis excluídas do modelo. O Teste de Restrições realizado é apresentado na parte inferior das tabelas a seguir, juntamente a outras estatísticas referentes aos modelos estimados.

Tabela 4_Descrição das Variáveis

\begin{tabular}{|c|c|c|c|c|}
\hline Variável & Média & $\begin{array}{l}\text { Desvio } \\
\text { Padrão }\end{array}$ & Mínimo & Máximo \\
\hline Duração dos Ajustes Fiscais & 1.458716 & 0.660136 & 1 & 4 \\
\hline \multicolumn{5}{|l|}{ Variáveis Estruturais } \\
\hline Número de Falhas & 1.715596 & 1.48506 & 0 & 7 \\
\hline Despesa de Pessoal/Receita Corrente Líquida & 0.4813684 & 0.1331321 & 17.327 & 78.7076 \\
\hline Receita Tributária/Receita Corrente & 0.5109637 & 0.2120523 & 0 & 84.6698 \\
\hline Impulso Fiscal & 0.028898 & 0.03553 & 0.00499 & 0.298401 \\
\hline Dummy Antes da Constituição & 0.137615 & 0.346086 & 0 & 1 \\
\hline Dummy Após Lei n. 9.496/97 & 0.284404 & 0.453214 & 0 & 1 \\
\hline Dummy para Ano Eleitoral & 0.0733945 & 0.2619875 & 0 & 1 \\
\hline Dummy Composição do Ajuste & 0.614679 & 0.488919 & 0 & 1 \\
\hline \multicolumn{5}{|l|}{ Variáveis Políticas } \\
\hline Dummy Permanência no Poder & 0.33945 & 0.47571 & 0 & 1 \\
\hline Polarização da Coligação & 0.161835 & 0.11043 & 0 & 0.45 \\
\hline Dummy Partido de Esquerda & 0.12844 & 0.336125 & 0 & 1 \\
\hline Fracionalização das Preferências & 0.576274 & 0.092096 & 0.31605 & 0.801129 \\
\hline . . . Partidos Efetivos & 5.215797 & 1.990139 & 1.946366 & 9.944806 \\
\hline
\end{tabular}




\subsection{2_ Modelo semiparamétrico com riscos proporcionais}

Os resultados obtidos por esse método são apresentados na Tabela 5, em que os coeficientes reportados referem-se à razão de risco, e sua interpretação difere da tradicionalmente utilizada para interpretar coeficientes. Quando os valores obtidos são maiores do que um, a variável relacionada à ra- zão desloca a função de risco básico para cima, ocorrendo o contrário quando a razão de risco estimada é menor do que um. Ou seja, quando um determinado coeficiente é maior (menor) que um, a elevação na variável à qual ele está associado leva a um aumento (redução) no risco, isto é, na probabilidade de saída da situação ajuste fiscal.

Tabela 5_Estimação Semiparamétrica - Modelo de Cox com Riscos Proporcionais

\begin{tabular}{|c|c|c|}
\hline \multirow{2}{*}{ Variáveis } & \multicolumn{2}{|c|}{ Razão de Risco } \\
\hline & Modelo (1) & Modelo (2) \\
\hline \multicolumn{3}{|l|}{ Variáveis Estruturais } \\
\hline Número de Falhas & $\begin{array}{l}1.139 \\
(0.02)\end{array}$ & $\begin{array}{l}1.113 \\
(0.06)\end{array}$ \\
\hline Despesa de Pessoal/Receita Corrente Líquida & $\begin{array}{l}1.009 \\
(0.05)\end{array}$ & $\begin{array}{l}1.010 \\
(0.02)\end{array}$ \\
\hline Receita Tributária/Receita Corrente & $\begin{array}{l}1.008 \\
(0.00)\end{array}$ & $\begin{array}{l}1.007 \\
(0.00)\end{array}$ \\
\hline Impulso Fiscal & $\begin{array}{r}37.323 \\
(0.00)\end{array}$ & $\begin{array}{r}70.696 \\
(0.00)\end{array}$ \\
\hline Dummy Antes da Constituição & $\begin{array}{l}1.366 \\
(0.04)\end{array}$ & $\begin{array}{l}1.407 \\
(0.03)\end{array}$ \\
\hline Dummy Após Lei n. 9.496/97 & $\begin{array}{l}0.470 \\
(0.00)\end{array}$ & $\begin{array}{l}0.455 \\
(0.00)\end{array}$ \\
\hline \multicolumn{3}{|l|}{ Controles Políticos } \\
\hline Polarização da Coligação & & $\begin{array}{l}1.011 \\
(0.03)\end{array}$ \\
\hline Número de Observações & 109 & 109 \\
\hline Log-verossimilhança & -423.42 & -422.88 \\
\hline Teste de Wald & $\begin{array}{r}37.69 \\
(0.00)\end{array}$ & $\begin{array}{r}41.61 \\
(0.00)\end{array}$ \\
\hline Teste de Restrições & $\begin{array}{r}1.18 \\
(0.56)\end{array}$ & $\begin{array}{r}7.23 \\
(0.41) \\
\end{array}$ \\
\hline
\end{tabular}

Fonte: Elaborada pelos autores.

Nota: P-Valor entre parênteses. 
Nos resultados, o Modelo 1 inclui somente as variáveis econômicas, enquanto o Modelo 2 inclui, além dessas, as variáveis políticas. Assim, o Número de Falhas, a razão Despesa com Pessoal/Receita Corrente Líquida e os anos anteriores à mudança constitucional aumentam a razão de risco, implicando menor probabilidade de manutenção do ajustamento fiscal. A Receita Tributária/Receita Corrente também implicou aumento na razão de risco. Isso indica que uma menor dependência de transferências leva a uma menor probabilidade de manutenção de ajustamento, dando suporte ao argumento da base econômica. Quanto maior a arrecadação conquanto fonte de receita, mais importante é do ponto de vista econômico o Estado e, portanto, maior a sua capacidade de obter financiamento para gastos adicionais e menor a probabilidade de manter os ajustamentos fiscais realizados. Vale mencionar que a importância da base econômica, vis-à-vis um eventual flypaper effect, como determinante do comportamento fiscal dos Estados brasileiros, foi verificada em Botelho (2002). O Impulso Fiscal também resultou num aumento da razão risco, indicando que, uma vez feito o ajustamento, a manutenção dele ou cortes adicionais são difíceis de ser feitos. Esse resultado encontra suporte em Illera e Mulas-Granados (2002) para as consolidações fiscais européias. Fi- nalmente, a Lei de Refinanciamento reduziu a razão risco, implicando uma mudança institucional importante na direção de maior controle das finanças estaduais.

A única variável política que apresentou significância foi a Polarização da Coligação. Quanto maior a polarização dos partidos, maior o viés deficitário e, portanto, menor a probabilidade de manutenção do ajustamento fiscal.

\subsubsection{Modelo paramétrico \\ com aceleração de saída}

Os resultados das estimativas com base nas distribuições exponencial, Weibull e loglogística, são apresentados respectivamente na Tabela 6.

Os coeficientes estimados dizem respeito ao efeito marginal de cada uma das variáveis explicativas sobre a duração esperada de um ajuste fiscal. Para quase todos os modelos, os resultados das estimações paramétricas corroboram os resultados obtidos com o modelo de Cox. A principal exceção é a dummy de Permanência no Poder, que não aparecia anteriormente e que agora aparece como significante nas especificações exponencial e Weibull. Ela aparece com sinal negativo indicando que, quanto maior a permanência no poder, menor a duração do ajustamento, dando suporte aos modelos de ciclo orçamentários oportunistas. 
Tabela 6_Estimação Paramétrica - Modelo de Aceleração de Saída

\begin{tabular}{|c|c|c|c|c|c|c|}
\hline \multirow[t]{2}{*}{ Variáveis } & \multicolumn{2}{|c|}{$\begin{array}{l}\text { Ditribuição } \\
\text { Exponencial }\end{array}$} & \multicolumn{2}{|c|}{$\begin{array}{c}\text { Ditribuição } \\
\text { Weibull }\end{array}$} & \multicolumn{2}{|c|}{$\begin{array}{c}\text { Ditribuição } \\
\text { Log-Logística }\end{array}$} \\
\hline & Modelo (1) & Modelo (2) & Modelo (1) & Modelo (2) & Modelo (1) & Modelo (2) \\
\hline \multicolumn{7}{|l|}{ Variáveis Estruturais } \\
\hline Número de Falhas & $\begin{array}{r}-0.079 \\
(0.08) \\
\end{array}$ & & $\begin{array}{r}-0.110 \\
(0.00) \\
\end{array}$ & $\begin{array}{r}-0.096 \\
(0.00) \\
\end{array}$ & $\begin{array}{r}-0.10 \\
(0.00)\end{array}$ & $\begin{array}{r}-0.088 \\
(0.01)\end{array}$ \\
\hline Despesa de Pessoal/Receita Corrente Líquida & $\begin{array}{r}-0.006 \\
(0.03) \\
\end{array}$ & $\begin{array}{r}-0.009 \\
(0.00) \\
\end{array}$ & $\begin{array}{r}-0.005 \\
(0.05) \\
\end{array}$ & $\begin{array}{r}-0.007 \\
(0.01) \\
\end{array}$ & $\begin{array}{r}-0.005 \\
(0.09) \\
\end{array}$ & $\begin{array}{r}-0.006 \\
(0.04) \\
\end{array}$ \\
\hline Receita Tributária/Receita Corrente & $\begin{array}{r}-0.005 \\
(0.00) \\
\end{array}$ & $\begin{array}{r}-0.005 \\
(0.00) \\
\end{array}$ & $\begin{array}{r}-0.006 \\
(0.00) \\
\end{array}$ & $\begin{array}{r}-0.005 \\
(0.00) \\
\end{array}$ & $\begin{array}{r}-0.006 \\
(0.00) \\
\end{array}$ & $\begin{array}{r}-0.005 \\
(0.00) \\
\end{array}$ \\
\hline Impulso Fiscal & $\begin{array}{r}-2.526 \\
(0.00) \\
\end{array}$ & $\begin{array}{r}-2.952 \\
(0.00)\end{array}$ & $\begin{array}{r}-2.849 \\
(0.00) \\
\end{array}$ & $\begin{array}{r}-3.453 \\
(0.00) \\
\end{array}$ & $\begin{array}{r}-2.191 \\
(0.00) \\
\end{array}$ & $\begin{array}{r}-2.476 \\
(0.00) \\
\end{array}$ \\
\hline Dummy Antes da Constituição & $\begin{array}{r}-0.198 \\
(0.07) \\
\end{array}$ & & $\begin{array}{r}-0.282 \\
(0.00) \\
\end{array}$ & $\begin{array}{r}-0.239 \\
(0.02) \\
\end{array}$ & $\begin{array}{r}-0.191 \\
(0.08) \\
\end{array}$ & $\begin{array}{r}-0.231 \\
(0.03) \\
\end{array}$ \\
\hline Dummy Após Lei n. 9.496/97 & $\begin{array}{l}0.565 \\
(0.00) \\
\end{array}$ & $\begin{array}{l}0.558 \\
(0.00) \\
\end{array}$ & $\begin{array}{l}0.444 \\
(0.00) \\
\end{array}$ & $\begin{array}{l}0.502 \\
(0.00) \\
\end{array}$ & $\begin{array}{l}0.442 \\
(0.00) \\
\end{array}$ & $\begin{array}{l}0.462 \\
(0.00) \\
\end{array}$ \\
\hline \multicolumn{7}{|l|}{ Controles Políticos } \\
\hline Dummy Permanência no Poder & & $\begin{array}{r}-0.169 \\
(0.06)\end{array}$ & & $\begin{array}{r}-0.142 \\
(0.09)\end{array}$ & & \\
\hline Polarização da Coligação & & $\begin{array}{r}-0.009 \\
(0.01)\end{array}$ & & $\begin{array}{r}-0.008 \\
(0.01)\end{array}$ & & $\begin{array}{r}-0.007 \\
(0.05)\end{array}$ \\
\hline Número de Observações & 109 & 109 & 109 & 109 & 109 & 109 \\
\hline Log-verossimilhança & -113.84 & -113.69 & -47.02 & -43.54 & -42.07 & -40.04 \\
\hline Teste de Wald & $\begin{array}{l}58.65 \\
(0.00) \\
\end{array}$ & $\begin{array}{l}62.76 \\
(0.00) \\
\end{array}$ & $\begin{array}{l}73.41 \\
(0.00) \\
\end{array}$ & $\begin{array}{r}106.96 \\
(0.00) \\
\end{array}$ & $\begin{array}{l}48.58 \\
(0.00) \\
\end{array}$ & $\begin{array}{l}59.94 \\
(0.00) \\
\end{array}$ \\
\hline Teste de Restrições & $\begin{array}{r}2.04 \\
(0.36) \\
\end{array}$ & $\begin{array}{r}9.98 \\
(0.27) \\
\end{array}$ & $\begin{array}{r}1.49 \\
(0.47) \\
\end{array}$ & $\begin{array}{r}4.93 \\
(0.55)\end{array}$ & $\begin{array}{r}0.56 \\
(0.75) \\
\end{array}$ & $\begin{array}{r}9.42 \\
(0.22)\end{array}$ \\
\hline AIC & 243.68 & 243.38 & 112.04 & 109.08 & 102.14 & 100.08 \\
\hline
\end{tabular}

Fonte: Elaborada pelos autores.

Nota: P-Valor entre parênteses. 
A escolha entre as três parametrizações não se mostra um problema fundamental neste caso, uma vez que os resultados são, qualitativa e quantitativamente, bastante semelhantes, independentemente da distribuição empregada. Ainda assim, a título de comparação, a Figura 1 do Anexo apresenta os resíduos de Cox-Snell (1968) para avaliar o ajuste das três especificações paramétricas. Os resíduos de Cox-Snell são definidos por:

$\hat{e}=-\log S\left(\frac{t}{X, \beta}\right)$

onde $S\left(\frac{t}{X, \beta}\right)$ é a função de sobrevivên-

cia estimada. Se o modelo estimado é correto, esses resíduos devem ter distribuição exponencial com função risco igual a 1. Dessa forma, os resíduos estimados podem ser usados como variável de duração e ter a respectiva função de sobrevivência obtida via método de Kaplan-Meier. Assim, o gráfico conjunto dos resíduos de Cox-Snell e do inverso aditivo do logaritmo natural da respectiva função sobrevivência nos dá uma noção do grau de adequação do modelo estimado. Os resíduos devem aproximar-se o máximo possível da linha reta com inclinação igual a 1 e começando da origem. Como pode ser visto, a figura para a forma funcional
Exponencial atende a esses requisitos a menor parte do tempo, apresentando, portanto, o pior ajuste. É importante destacar que esse padrão se repetirá para os demais modelos reportados ao longo do trabalho.

O melhor ajuste relativo das distribuições Weibull e Log-logística pode ser atestado ainda por meio do Critério de Informação de Akaike (AIC), reportado nas tabelas que contêm os resultados dos modelos paramétricos. A estatística AIC é bastante empregada para a comparação de modelos "não-encaixados", levando em consideração a log-verossimilhança e o número de parâmetros (n) do modelo estimado: AIC $=-2($ Log-verossimilhança $)-2(n+1)$

Fica claro por essa expressão que o modelo preferido é aquele que apresentar o menor valor para a estatística AIC. Como pode ser observado na Tabela 6, e nas demais deste trabalho, segundo este critério, $\mathrm{O}$ ajuste apresentado pelas distribuições Weibull e Log-logística é superior ao da Exponencial. Esse resultado pode ser indicativo de que a função de risco associado à duração dos ajustes fiscais dos Estados brasileiros apresenta dependência temporal nãoconstante. Como já indicara o estimador de Kaplan-Meier, a probabilidade de encerramento de um episódio de consolidação fiscal se eleva fortemente após os pri- 
meiros anos, o que encontra suporte nos resultados descritos acima.

Dado o caráter ambíguo do sinal das variáveis Receita Tributária/Receita Corrente e Impulso Fiscal, resolveu-se reestimar os modelos sem essas variáveis para verificar se as demais permaneciam significantes e com os sinais esperados. A idéia é verificar se a inclu- são dessas variáveis, cujos efeitos sobre os ajustes fiscais estaduais são controversos, dáse ao custo de mudanças relevantes nos coeficientes estimados para as demais variáveis. Como veremos a seguir, não é esse o caso. Os resultados para o modelo de Cox estendido são apresentados na Tabela 7.

Tabela 7_ Estimação Semiparamétrica - Modelo de Cox com Riscos Proporcionais, excluindo Receita Tributária/Receita Corrente e Impulso Fiscal

\begin{tabular}{|c|c|c|}
\hline \multirow{2}{*}{ Variáveis } & \multicolumn{2}{|c|}{ Razão de Risco } \\
\hline & Modelo (1) & Modelo (2) \\
\hline \multicolumn{3}{|l|}{ Variáveis Estruturais } \\
\hline Número de falhas & $\begin{array}{l}1.149 \\
(0.01)\end{array}$ & $\begin{array}{l}1.116 \\
(0.06)\end{array}$ \\
\hline Despesa de Pessoal/Receita Corrente Líquida & $\begin{array}{l}1.008 \\
(0.04)\end{array}$ & $\begin{array}{l}1.010 \\
(0.02)\end{array}$ \\
\hline Dummy Antes da Constituição & $\begin{array}{l}1.315 \\
(0.08)\end{array}$ & $\begin{array}{l}1.343 \\
(0.06)\end{array}$ \\
\hline Dummy Após Lei n. 9.496/97 & $\begin{array}{l}0.456 \\
(0.00)\end{array}$ & $\begin{array}{l}0.444 \\
(0.00)\end{array}$ \\
\hline \multicolumn{3}{|l|}{ Controles Políticos } \\
\hline Polarização da Coligação & & $\begin{array}{l}1.011 \\
(0.03)\end{array}$ \\
\hline Número de Observações & 109 & 109 \\
\hline Log-verossimilhança & -424.95 & -424.31 \\
\hline Teste de Wald & $\begin{array}{c}17.99 \\
(0.00)\end{array}$ & $\begin{array}{l}20.87 \\
(0.00)\end{array}$ \\
\hline Teste de Restrições & $\begin{array}{r}2.68 \\
(0.26)\end{array}$ & $\begin{array}{r}7.41 \\
(0.38)\end{array}$ \\
\hline
\end{tabular}

Fonte: Elaborada pelos autores.

Nota: P-Valor entre parênteses. 
Os resultados não se alteram. O Número de Falhas, a razão Despesa com Pessoal/ Receita Corrente Líquida e a dummy para os anos anteriores à Constituição são responsáveis por um aumento da razão risco. Por outro lado, a Lei de Refinanciamento n. 9.496/97 levou a uma redução da razão risco. Como anteriormente, a Polarização da Coligação aparece como a única variável política que influencia a duração dos ajustamentos fiscais.

A Tabela 8 apresenta os resultados das estimações paramétricas.

A principal mudança é com relação à variável Permanência no Poder, que antes aparecia como estatisticamente significante nas especificações exponencial e Weibull e agora não aparece em nenhuma das especificações. Os resíduos de Cox-Snell são apresentados na Figura 2 do Anexo.

\section{5_Avaliação dos resultados com outra definição de ajustamento fiscal}

Um argumento possível contra o critério de classificação do desempenho fiscal adotado anteriormente é o de que melhoras no resultado primário não implicam reduções no endividamento e, portanto, não caracterizam corretamente a postura fiscal. Assim, uma alternativa seria seguir Botelho (2002) para classificar a postura fiscal dos Estados. Para tanto, ele utiliza os conceitos definidos pela Portaria do Ministério da Fazenda n. 089/97, que estabelece metodologia de cálculo da capacidade de pagamento para fins de concessão de garantia para empréstimos a ser avalizados pelo Tesouro.

Seguindo um padrão contábil simplificado para as finanças públicas estaduais, podemos definir o Resultado Primário (SP) e a Necessidade de Financiamento Líquida (NFL) por:

$S P=($ receita total - receitas financeiras receitas de operações de crédito) (despesa total-despesas de juros e encargos - despesas de amortizações);

NFL $=-S P+$ juros da dívida (líquido devido).

Botelho (2002) classifica, então, a postura fiscal dos Estados como:

_ Categoria "A": quando a necessidade de financiamento líquida é negativa e superior, em módulo, aos juros líquidos devidos.

_ Categoria "B": quando a necessidade de financiamento líquida é negativa, porém inferior, em módulo, aos juros líquidos devidos.

_Categoria "C": quando a necessidade de financiamento líquida e o resultado primário são positivos.

_ Categoria "D”: quando o resultado primário é negativo. 
Tabela 8_ Estimação Paramétrica - Modelo de Aceleração de Saída, excluindo "Receita Tributária"/"Receita Corrente" e "Impulso Fiscal"

\begin{tabular}{|c|c|c|c|c|c|c|}
\hline \multirow{2}{*}{ Variáveis } & \multicolumn{2}{|c|}{$\begin{array}{l}\text { Distribuição } \\
\text { Exponencial }\end{array}$} & \multicolumn{2}{|c|}{$\begin{array}{c}\text { Distribuição } \\
\text { Weibull }\end{array}$} & \multicolumn{2}{|c|}{$\begin{array}{l}\text { Distribuição } \\
\text { Log-Logística }\end{array}$} \\
\hline & Modelo (1) & Modelo (2) & Modelo (1) & Modelo (2) & Modelo (1) & Modelo (2) \\
\hline \multicolumn{7}{|l|}{ Variáveis Estruturais } \\
\hline Número de falhas & -0.069 & & -0.124 & -0.098 & -0.085 & -0.094 \\
\hline Despesa de Pessoal/Receita Corrente Líquida & $\begin{array}{r}-0.006 \\
(0.04)\end{array}$ & $\begin{array}{r}-0.008 \\
(0.00)\end{array}$ & $\begin{array}{r}-0.005 \\
(0.04)\end{array}$ & $\begin{array}{r}-0.006 \\
(0.02)\end{array}$ & $\begin{array}{r}-0.006 \\
(0.08)\end{array}$ & $\begin{array}{r}-0.007 \\
(0.03)\end{array}$ \\
\hline Dummy Antes da Constituição & & & $\begin{array}{r}-0.253 \\
(0.02)\end{array}$ & $\begin{array}{r}-0.248 \\
(0.02)\end{array}$ & & $\begin{array}{r}-0.231 \\
(0.06)\end{array}$ \\
\hline Dummy Após Lei n. 9.496/97 & $\begin{array}{l}0.598 \\
(0.00)\end{array}$ & $\begin{array}{l}0.526 \\
(0.00)\end{array}$ & $\begin{array}{l}0.509 \\
(0.00)\end{array}$ & $\begin{array}{l}0.496 \\
(0.00)\end{array}$ & $\begin{array}{l}0.467 \\
(0.00)\end{array}$ & $\begin{array}{l}0.498 \\
(0.00)\end{array}$ \\
\hline \multicolumn{7}{|l|}{ Controles Políticos } \\
\hline Polarização da Coligação & & $\begin{array}{r}-0.008 \\
(0.03)\end{array}$ & & $\begin{array}{r}-0.007 \\
(0.02)\end{array}$ & & $\begin{array}{r}-0.008 \\
(0.06)\end{array}$ \\
\hline Número de Observações & 109 & 109 & 109 & 109 & 109 & 109 \\
\hline Log-verossimilhança & -114.73 & -114.64 & -53.67 & -51.38 & -50.22 & -46.53 \\
\hline Teste de Wald & $\begin{array}{l}21.15 \\
(0.00)\end{array}$ & $\begin{array}{l}26.55 \\
(0.00)\end{array}$ & $\begin{array}{l}26.69 \\
(0.00)\end{array}$ & $\begin{array}{l}38.33 \\
(0.00)\end{array}$ & $\begin{array}{l}16.26 \\
(0.00)\end{array}$ & $\begin{array}{l}23.19 \\
(0.00)\end{array}$ \\
\hline Teste de Restrições & $\begin{array}{r}5.71 \\
(0.13)\end{array}$ & $\begin{array}{l}12.48 \\
(0.19)\end{array}$ & $\begin{array}{r}1.88 \\
(0.39)\end{array}$ & $\begin{array}{l}10.92 \\
(0.14)\end{array}$ & $\begin{array}{r}5.44 \\
(0.14)\end{array}$ & $\begin{array}{r}7.59 \\
(0.37)\end{array}$ \\
\hline AIC & 239.46 & 239.28 & 121.34 & 118.76 & 112.44 & 109.06 \\
\hline
\end{tabular}

Fonte: Elaborada pelos autores.

Nota: P-Valor entre parênteses.

Assim, Estados classificados nas categorias "A" e "B" seriam tidos como tendo um desempenho fiscal adequado. Isso porque essas categorias implicam a manutenção ou redução do endividamento público. Por outro lado, Estados classificados nas categorias "C" e " $\mathrm{D}$ ", que resultam em aumento do endividamento público, seriam tidos como tendo um desempenho fiscal inadequado.

Um ajuste fiscal, seguindo essa conceituação, foi definido por uma melhora na 
postura fiscal do Estado, partindo de qualquer uma das classificações acima. A duração de um ajustamento fiscal, portanto, foi denotada pelo número de períodos durante os quais o Estado permaneceu sem que sua postura fiscal regredisse.

A idéia é verificar a probabilidade de manutenção de um dado desempenho fis- cal ou de uma postura fiscal. Em outros termos, anteriormente se olhava para uma mudança no saldo fiscal. Agora, olha-se para as implicações de um dado saldo fiscal para a manutenção ou redução do endividamento. Acredita-se que o exercício vale a pena, em termos de trazer evidências adicionais para perguntas que são correlacionadas.

\section{Tabela 9_ Estimação Paramétrica usando critério de classificação de Botelho Modelo de Aceleração de Saída}

\begin{tabular}{|c|c|c|c|}
\hline \multirow{2}{*}{ Variáveis } & \multicolumn{3}{|c|}{ Distribuição } \\
\hline & Exponencial & Weibull & Log-Logística \\
\hline \multicolumn{4}{|l|}{ Variáveis Estruturais } \\
\hline Número de Falhas & $\begin{array}{r}-0.140 \\
(0.01)\end{array}$ & $\begin{array}{r}-0.154 \\
(0.00)\end{array}$ & $\begin{array}{r}-0.109 \\
(0.01)\end{array}$ \\
\hline Despesa de Pessoal/Receita Corrente Líquida & $\begin{array}{r}-0.006 \\
(0.09)\end{array}$ & $\begin{array}{r}-0.008 \\
(0.06)\end{array}$ & \\
\hline Impulso Fiscal & $\begin{array}{r}-7.315 \\
(0.00)\end{array}$ & $\begin{array}{r}-6.89 \\
(0.00)\end{array}$ & $\begin{array}{r}-5.47 \\
(0.00)\end{array}$ \\
\hline Dummy antes da Constituição & $\begin{array}{r}-0.433 \\
(0.00)\end{array}$ & $\begin{array}{r}-0.545 \\
(0.00)\end{array}$ & $\begin{array}{r}-0.385 \\
(0.01)\end{array}$ \\
\hline Dummy após Lei n. 9.496/97 & $\begin{array}{l}0.463 \\
(0.01)\end{array}$ & $\begin{array}{l}0.364 \\
(0.00)\end{array}$ & \\
\hline Número de Observações & 90 & 90 & 90 \\
\hline Log-verossimilhança & -97.15 & -56.89 & -53.75 \\
\hline Teste de Wald & $\begin{array}{l}44.29 \\
(0.00)\end{array}$ & $\begin{array}{c}83.14 \\
(0.00)\end{array}$ & $\begin{array}{c}35.18 \\
(0.00)\end{array}$ \\
\hline Teste de Restrições & $\begin{array}{r}1.07 \\
(0.78)\end{array}$ & $\begin{array}{r}1.38 \\
(0.71)\end{array}$ & $\begin{array}{l}10.74 \\
(0.06)\end{array}$ \\
\hline AIC & 208.3 & 129.78 & 119.5 \\
\hline
\end{tabular}

Fonte: Elaborada pelos autores.

Nota: P-Valor entre parênteses. 
As principais mudanças são a nãosignificância da variável Receita Tributária/Receita Corrente e a não-significância de qualquer variável política. As demais variáveis permanecem significantes e com os sinais esperados. Quanto maior o Número de Falhas, maior os Gastos com Pessoal, e, quanto maior o tamanho do ajuste, menor a manutenção da postura fiscal nas categorias superiores. A Lei de Refinanciamento fez com que aumentasse a probabilidade de o Estado continuar sendo classificado nas categorias superiores.
A avaliação dos resíduos de Cox-Snell indica, mais uma vez, que a forma funcional Exponencial é a que apresenta o pior ajuste, satisfazendo o requisito de otimalidade a menor parte do tempo, relativamente às distribuições de Weibull e Log-logística (Figura 3 do Anexo).

Finalmente, também foram refeitas as estimativas desconsiderando-se a variável de impulso fiscal. Os resultados são apresentados na Tabela 10 .

\section{Tabela 10_ Estimação Paramétrica usando critério de classificação de Botelho Modelo de Aceleração de Saída}

\begin{tabular}{|c|c|c|c|}
\hline \multirow{2}{*}{ Variáveis } & \multicolumn{3}{|c|}{ Distribuição } \\
\hline & Exponencial & Weibull & Log-Logística \\
\hline \multicolumn{4}{|l|}{ Variáveis Estruturais } \\
\hline Número de Falhas & $\begin{array}{c}-0.118 \\
(0.049)\end{array}$ & $\begin{array}{r}-0.128 \\
(0.00)\end{array}$ & $\begin{array}{r}-0.097 \\
(0.04)\end{array}$ \\
\hline Despesa de Pessoal/Receita Corrente Líquida & $\begin{array}{r}-0.008 \\
(0.02)\end{array}$ & $\begin{array}{r}-0.009 \\
(0.03)\end{array}$ & $\begin{array}{r}-0.007 \\
(0.01)\end{array}$ \\
\hline Dummy Antes da Constituição & $\begin{array}{r}-0.555 \\
(0.00)\end{array}$ & $\begin{array}{r}-0.657 \\
(0.00)\end{array}$ & $\begin{array}{r}-0.476 \\
(0.00)\end{array}$ \\
\hline Dummy Após Lei n. 9.496/97 & $\begin{array}{l}0.352 \\
(0.05)\end{array}$ & $\begin{array}{l}0.277 \\
(0.05)\end{array}$ & \\
\hline Número de Observações & 90 & 90 & 90 \\
\hline Teste de Wald & $\begin{array}{l}21.80 \\
(0.00)\end{array}$ & $\begin{array}{l}28.05 \\
(0.00)\end{array}$ & $\begin{array}{l}18.07 \\
(0.00)\end{array}$ \\
\hline Log-verossimilhança & -98.44 & -62.94 & -56.44 \\
\hline Teste de Restrições & $\begin{array}{r}4.28 \\
(0.83)\end{array}$ & $\begin{array}{r}5.19 \\
(0.73)\end{array}$ & $\begin{array}{r}3.21 \\
(0.95)\end{array}$ \\
\hline Teste de Restrições & 208.88 & 139.88 & 124.88 \\
\hline
\end{tabular}

Fonte: Elaborada pelos autores.

Nota: P-Valor entre parênteses. 
As variáveis que apareciam como estatisticamente importantes continuam a mostrar significância, e nenhuma variável política parece determinar a duração. Os resíduos de Cox-Snell são apresentados na Figura 4 do Anexo.

\section{6_Conclusões}

O objetivo deste artigo é examinar a persistência das consolidações fiscais dos Estados brasileiros no período 1986-2001, usando a metodologia dos modelos de duração. Foram estudados os intervalos de tempo entre duas expansões fiscais, ou seja, o número de anos entre o começo e o fim de um episódio de consolidação fiscal. Acredita-se que uma análise sistemática da duração das consolidações fiscais dos Estados é importante para um melhor entendimento dos determinantes das experiências de ajustamento fiscal, que têm se mostrado extremamente curtas.

A análise inicial não-paramétrica sugere que a probabilidade de que uma consolidação fiscal seja mantida cai rapidamente depois do primeiro ano e decresce dramaticamente depois do segundo ano.

A análise paramétrica foi feita buscando-se controlar para mais variáveis, além do tempo, que pudessem influenciar a probabilidade de uma consolidação fiscal ter- minar. Várias especificações foram testadas, e as variáveis que apareceram, de forma robusta, como determinantes foram: o Número de Falhas, a razão Despesa com Pessoal/Receita Corrente Líquida, a dummy para a Constituição de 1988, a dummy para a Lei de Refinanciamento n. 9.496/97 e a Polariração da Coligação.

Assim, o maior comprometimento das receitas com despesas de difícil corte (despesa com pessoal) e a reputação acumulada de desistências de ajustes anteriores, em geral, estão associados a menores probabilidades de manutenção de ajustes fiscais.

Além disso, os resultados lançaram luz sobre as variáveis fiscais Receita Tributária / Receita Corrente e Impulso Fiscal, cujos impactos esperados teoricamente sobre a duração dos ajustes eram considerados inicialmente ambíguos. Quanto maior a arrecadação conquanto fonte de receita, mais importante é do ponto de vista econômico o Estado e, portanto, maior a sua capacidade de obter financiamento para gastos adicionais e menor a probabilidade de manter os ajustamentos fiscais realizados. O Impulso Fiscal também resultou num aumento da razão risco, indicando que, uma vez feito o ajustamento, a manutenção dele ou cortes adicionais são difíceis de ser feitos.

Do ponto de vista político, deve ser destacada a pouca significância estatística 
das variáveis testadas para a determinação das durações dos ajustes fiscais nos Estados brasileiros. A exceção é o viés deficitário revelado pela variável de polarização das preferências da coligação.

Por fim, os resultados mostram que a Constituição Federal de 1988 e a Lei de Refinanciamento de 1997 constituem-se institutos que tiveram importantes reflexos fiscais. Tais mudanças institucionais mostraram-se importantes na direção de maior controle das finanças estaduais, fazendo com que os ajustes fiscais nos anos posteriores às suas promulgações estivessem associados a menores probabilidades de término.

O impacto positivo da Constituição e da Lei de Refinanciamento é particularmente interessante. Isso porque Poterba (1996, 1997), entre outros, sugere que mudanças nas regras fiscais e, de modo mais geral, nas instituições fiscais podem afetar o resultado da política fiscal. Ainda que o foco sejam as taxas de gasto e o crescimento da taxação, ${ }^{14}$ a evidência aqui obtida seria uma primeira indicação de que o impacto das mudanças institucionais também poderia ocorrer sobre a duração dos ajustamentos fiscais.

Sugestões para pesquisa futura envolvem a análise de sensibilidade para critérios mais severos para classificação do desempenho fiscal. Como observado anteriormente, infelizmente, para o período amostral anali- sado, isso não foi possível. Entretanto, quando forem disponibilizadas informações para o período mais recente (depois de 2001), eventualmente, seja possível obter observações suficientes. Outra questão relevante seria avaliar a presença de heterogeneidade temporal e/ou espacial e a robustez dos resultados a essa possível heterogeneidade.

\footnotetext{
4 Stansel (1994) mostra que a taxa de crescimento relativa dos gastos dos Estados americanos que adotaram limites para os gastos e impostos se reduziu significativamente depois da adoção desses limites. Bayoumi e Eichengreen (1994), por outro lado, argumentam que limites aos gastos e impostos reduzem a probabilidade de episódios futuros de endividamento excessivo e, portanto, de probabilidade de default, olhando também os Estados americanos.
} 


\section{Referências bibliográficas}

\author{
ALESINA, A.; PEROTTI, R. \\ Fiscal adjustments in OECD \\ countries: composition and \\ macroeconomic effects. \\ IMF Staff Papers, v. 44, n. 2, \\ p. 210-248, 1997.
}

ALESINA, A.; ROSENTHAL, H. Partisan politics, divide government, and the economy. Cambridge: Cambridge University Press, 1995

ALESINA, A.; TABELLINI, G A positive theory of fiscal deficits and government debt in a democracy. 1987. (NBER Working Paper, n. 2308)

ALT, J.; LOWRY, R. Divided government, fiscal institutions and budget deficits: evidence from the states. American Political Science Review, v. 88, p. 811-829, 1994.

BEVILAQUA, A. S.; WERNECK, R. L. F. Fiscal impulse in the Brazilian economy, 1989-1996. Departamento de Economia PUC-Rio, out. 1997. (Texto para Discussão, n. 379).

BLANCHARD, O. Suggestions for a new set of fiscal indicators. OECD Economics and Statistics Department, April 1990. (Working Paper, n. 79).

BOTELHO, R. Determinantes do comportamento fiscal dos estados brasileiros. 2002. Dissertação (mestrado) - Departamento de Economia da Faculdade de Economia, Administração e Contabilidade da Universidade de São Paulo, São Paulo, 2002.
CHAND, S. K. Mensuração do impulso fiscal e seu impacto. In: BLEJER, M. I.; CHEASTY, A. (Org.). Como medir o déficit público: questões analíticas e metodológicas, Secretaria do Tesouro Nacional, 1999

CossíO, F. A. B. Comportamento fiscal dos governos estaduais brasileiros: determinantes políticos e efeitos sobre o bem estar dos seus estados. Brasília: Editora da UnB, 2001. (Monografia agraciada com menção honrosa no V Prêmio de Monografia da Secretaria do Tesouro Nacional - Tópicos Especiais de Finanças Públicas).

COX, D. R.; OAKES, D. Analysis of survival data. London: Chapman e Hall, 1984.

COX, D. R.; SNELL, E. J. A general definition of residuals. Journal of the Royal Statistical Society, Series B, v. 39, p. 248-275, 1968.

EICHENGREEN, B. BAYOUMI, T.; The political economy of fiscal restrictions: implications from Europe from the United States. European

Economic Review, v. 38, p. 783-791, 1994.

GRILLI, V., MASCIANDARO, D.; TABELLINI, G. Political and monetary institutions and public finance policies in the industrial democracies, Economic Policy, n. 13, 1991.
ILLERA, R. M.;

MULAS-GRANADOS, C.

Duration of fiscal budgetary consolidations in the European Union. European Economic Group, 2002. (Working Paper, n. 18).

KAPLAN, E. L.; MEIER, P. Non-parametric estimation for incomplete observations. Journal of American Statistical Association, v. 53 , p. $457-481,1958$

KIEFER, N. M. Economic duration data and hazard functions. Journal of Economic Literature, v. 26, p. 646-679, 1988.

KONTOPOULOS, C. PEROTTI, R. In: POTERBA, J.; HAGEN, J. V. Fiscal institutions and fiscal performance. University of Chicago: Chicago University Press, 1999.

LIMA JÚNIOR, O. B. de (Org.). O sistema partidário brasileiro: diversidade e tendências, 1982-94. Rio de Janeiro: Editora Fundação Getúlio Vargas, 1997.

McDERMOTT, J. C.;

WESCOTT, R. F. An empirical analysis of fiscal adjustments.

IMF Staff Papers, v. 43, n. 4, p. 725-753, 1996.

MENEGUIM, F. B.; BUGARIN, M. S. Reeleição e política fiscal: um estudo dos efeitos nos gastos públicos. Economia Aplicada, v. 5 , n. 3, p. 600-622, 2001.
POTERBA, J. Budget institutions and fiscal policy in the U. S. States. American Economic Review, v. 86, p. 395-400, 1996.

POTERBA, J. Do budget rules work? In: AUERBACH, A. (Ed.) Fiscal policy: lessons from empirical research. MIT Press, p. $53-86,1997$

ROGOFF, K.; SILBERT, A. Elections and Macroeconomic Policy Cycles. Review of Economic Studies, v. 55, n. 1, p. 1-16, 1988.

SCHNEIDER, A. Loyalty and voice: budget institutions in Brazilian states. Miami, USA, 2000). (Documento apresentado ao Encontro Annual da LASA).

SHI, M. Fiscal adjustments in Latin America: causes, success, and consequences. Department of Finance, University of Wisconsin - Madison, 2002. (mimeo.).

STANSEL, D. Taming leviathan: are tax and spending limits the answer? Policy Analysis, CATO Instituite, n. 213, 1994.

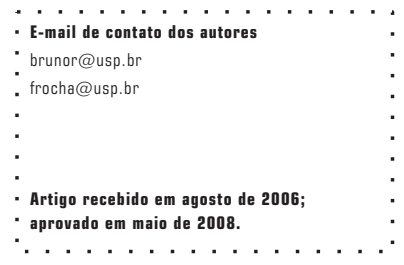


Figura 1_Resíduos de Cox-Snell para avaliar o ajuste dos três modelos paramétricos
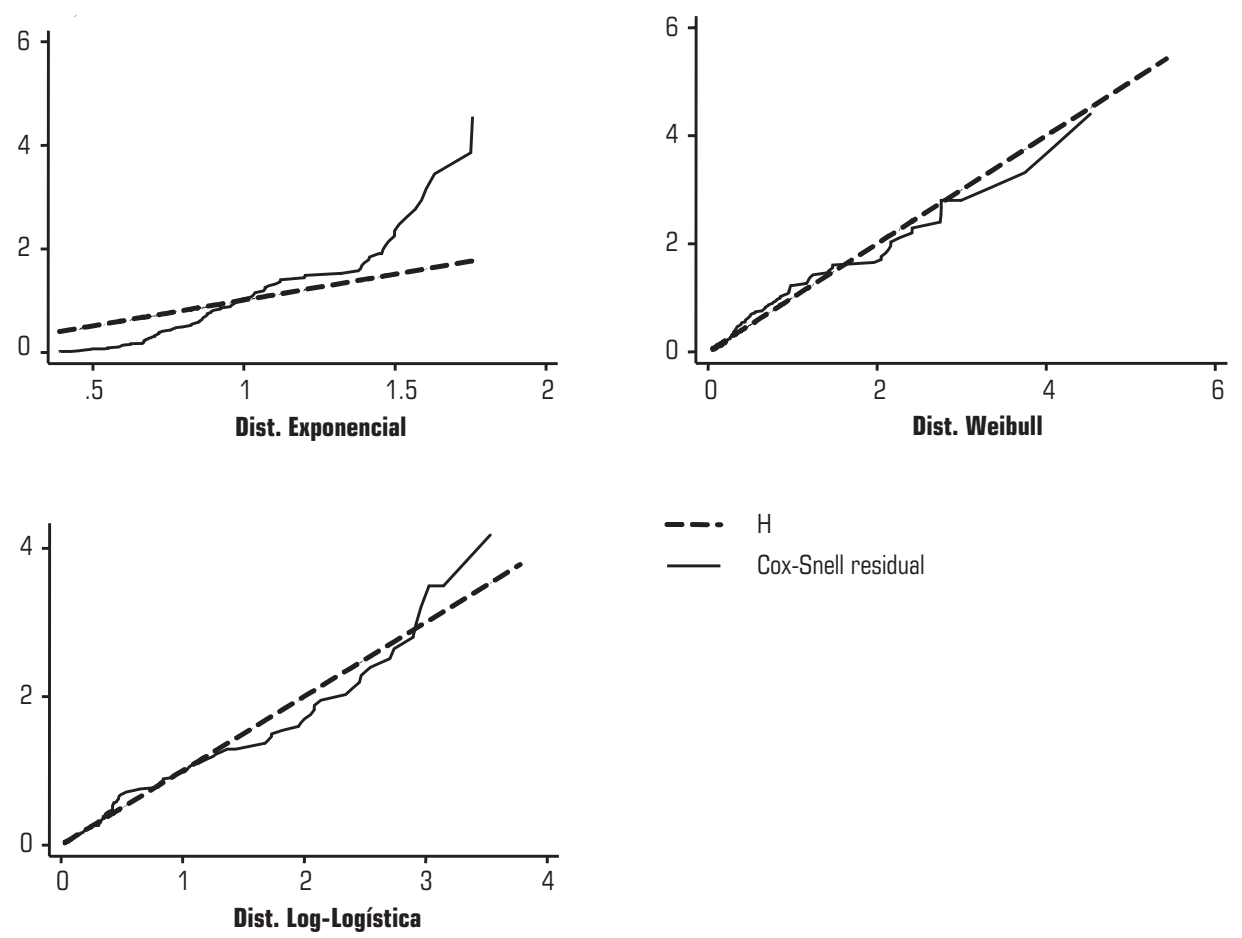

- - H

Cox-Snell residual

Fonte: Elaborada pelos autores

Nota: O critério de ajuste requer que os resíduos se aproximem o máximo possível da linha reta com inclinação igual a 1 e começando da origem. 
Figura 2_Resíduos de Cox-Snell para avaliar o ajuste dos três modelos paramétricos, excluindo Receita Tributária/Receita Corrente e Impulso Fiscal
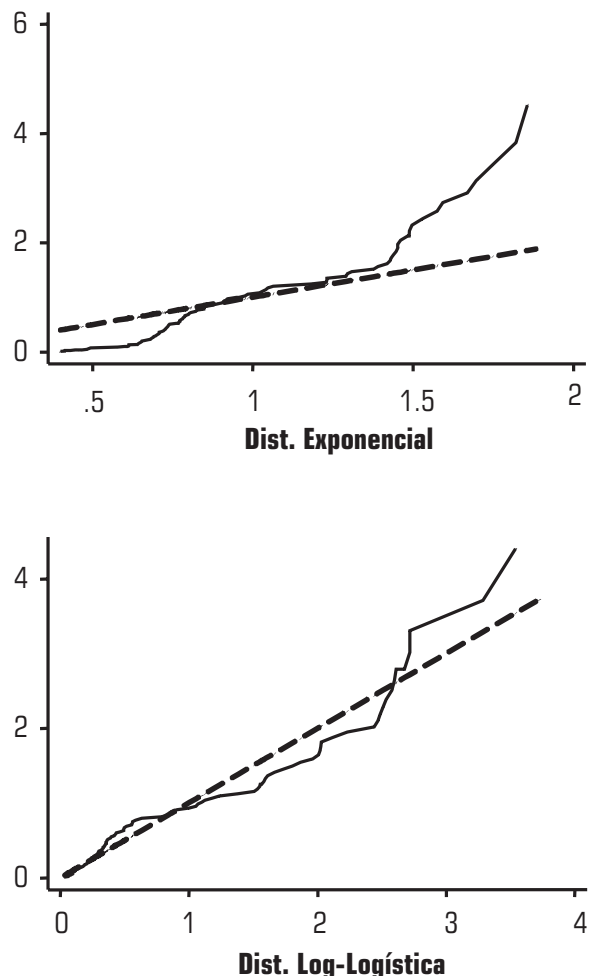

Fonte: Elaborada pelos autores.

Nota: O critério de ajuste requer que os resíduos se aproximem o máximo possível da linha reta com inclinação igual a 1 e começando da origem.

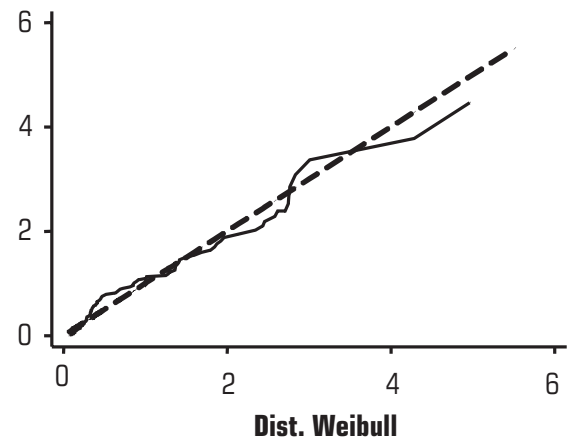

- - $\mathrm{H}$

Cox-Snell residual 
Figura 3_ Resíduos de Cox-Snell para avaliar o ajuste dos três modelos paramétricos, usando o critério de classificação de Botelho (2002)

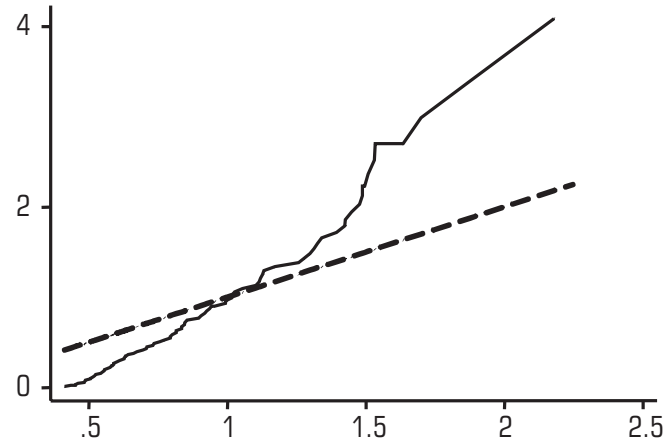

Dist. Exponencial

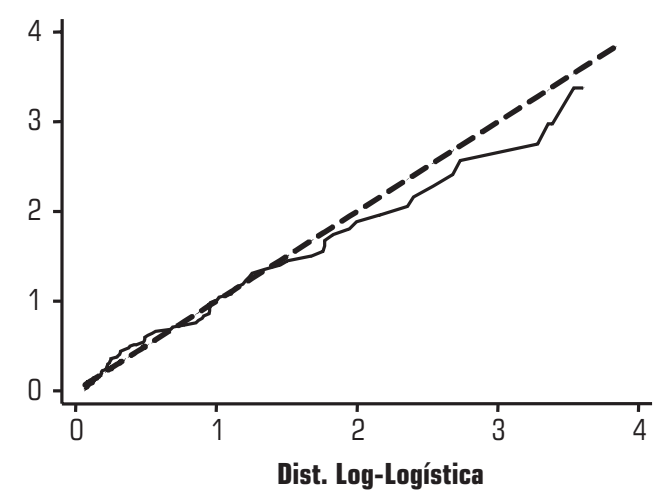

Fonte: Elaborada pelos autores.

Nota: O critério de ajuste requer que os resíduos se aproximem o máximo possível da linha reta com inclinação igual a 1 e começando da origem.

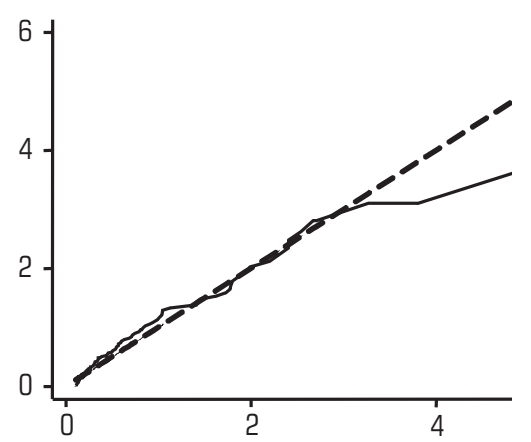

Dist. Weibull

- - H

Cox-Snell residual 
Figura 4_Resíduos de Cox-Snell para avaliar o ajuste dos três modelos paramétricos, usando o critério de classificação de Botelho (2002) e excluindo Receita Tributária/Receita Corrente e Impulso Fiscal
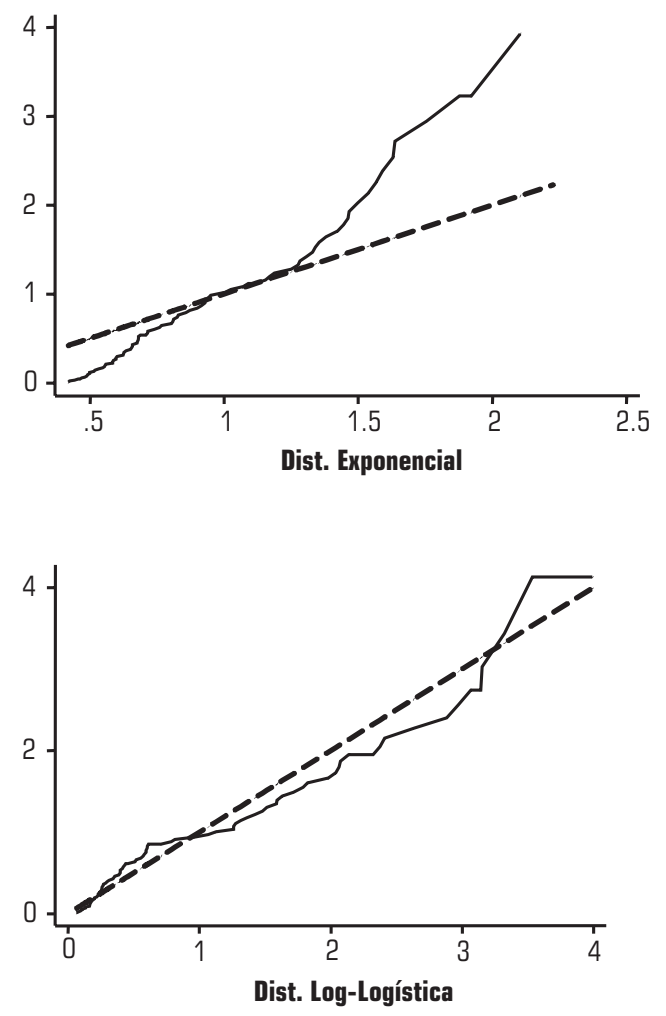

Fonte: Elaborada pelos autores.

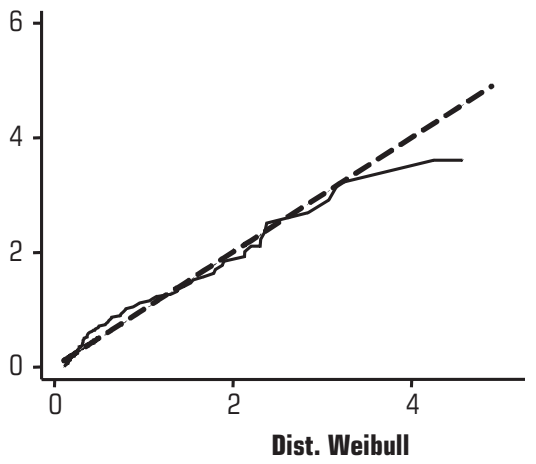

- - H

Cox-Snell residual

Nota: O critério de ajuste requer que os resíduos se aproximem o máximo possível da linha reta com inclinação igual a 1 e começando da origem. 